\title{
Perfil dos alunos de Ensino a Distância na Universidade Pedagógica de Moçambique-Niassa
}

\section{Profile of Distance Learning Students at the Pedagogical University of Mozambique-Niassa}

\author{
Dionísio Tumbo ***, Bento Silva** \\ *Universidade Pedagógica de Moçambique-Delegação de Niassa, **Universidade do Minho
}

\begin{abstract}
Resumo
Este artigo carateriza os alunos dos cursos em Educação a Distância (EAD), em idade, sexo, formação académica, situação laboral, anos de experiência profissional e os motivos de frequência em EAD. Aplicou-se um survey em 249 participantes, cujos resultados receberam tratamentos estatísticos no IBM® SPSS $®$. Concluiu-se com este estudo que metade dos alunos tem idades entre 31 a 40 anos, já com vínculo profissional, que a maioria exerce a função docente e opta por estes cursos em virtude de não ter que se deslocar à Universidade, compatibilidade de horários e atendimento aos interesses pessoais dos formandos. Palavras-Chave: Universidade Pedagógica Moçambique; Educação a Distância; Perfil dos Alunos da UP.
\end{abstract}

\begin{abstract}
This article characterizes the students of Distance Education (EAD) courses, according to their age, gender, academic background, employment status, years of professional experience, and the reasons for attending EAD. A survey was applied to 249 participants, whose results were statistically treated using IBM ${ }^{\circledR}$ SPSS ${ }^{\circledR}$ software. The study concludes that half of the students are aged between 31 to 40 years old, they are already employed, the majority of them pursue the teaching function, and opts for these courses because of limitation of time to attend face- to-face classes at University, compatibility of schedules, and to respond personal interests.
\end{abstract}

Keywords: Universidade Pedagógica de Moçambique; Distance Education; Profile of the UP students.

\section{Introdução}

Nos tempos que vivemos, em Moçambique assiste-se a uma inversa proporcionalidade entre a oferta pelas instituições formadoras e a procura expressiva de cursos superiores, por milhares de candidatos oriundos de todos os "cantos" do país. A insuficiência de infraestruturas (físicas e tecnológicas), recursos humanos e financeiros, são apontados, recorrentemente, como principais entraves para alargar as possibilidades de ingresso e frequência aos cursos presenciais.

A resposta a esta problemática parece estar em programas de educação e formação a distância. Esta modalidade funciona como grande catalisador e multiplicador de acesso ao conhecimento a muitas pessoas que, devido ao "custos de oportunidades" em tempo e espaço, não têm condições para aceder aos cursos em ambientes escolares de ensino presencial.

A educação a distância carateriza-se por ser uma modalidade que privilegia a autonomia do aluno. Verifica-se, nestes programas, uma rotura dos paradigmas tradicionais de ensino, nos quais a centralidade da decisão sobre aonde, quando e como estudar já não é da pertença da figura do professor.

Nesta conformidade, o principal escopo desta pesquisa foi de identificar e descrever o perfil dos alunos, especificamente dos cursos de Licenciatura em AGEAdministração e Gestão da Educação, EB-Ensino Básico e EI-Ensino de Inglês, oferecidos em regime de EAD na Universidade Pedagógica de Moçambique, Delegação de Niassa (UPNI).

O estudo começou com uma série de indagações, para apurar a distribuição dos alunos em termos de, idade, sexo, formação académica, situação laboral, anos de experiência profissional enquanto professor e os motivos de frequência do curso em EAD.

\section{Educação a distância: que conceito atribuir?}

A sondagem sistemática da literatura sobre o conceito da educação a distância inicia com reconhecimento de dificuldades e ambiguidades na sua delimitação. A verdade manda dizer que não se trata de algo de novo, pois existem relatos históricos que justificam que há milhares de anos foram difundidos patrimónios socioculturais e científicos da humanidade envolvendo navegantes que percorriam o mundo todo, levando como bagagem suas tradições, expressas em "crenças, conhecimento de barcos, arquitetura e ainda conceitos de estruturas sociais" (Duggleby, 2002, p.7). Neste sentido, a interação entre os povos, por meio da cultura representada na época (expressa pela lingugaem escrita e falada), favoreceu a difusão de conhecimentos, marcadamente pelos processos de educação e formação.

Nestes moldes, o conceito da EAD alberga um campo alargado de informações, não propiamente como modalidade de ensino, mas suas caraterísticas históricas, políticas e sociais próprias de abordagens em tempo e espaço. Segundo Santos (2014) o que carateriza a 
educação a distância é principalmente a "separação física entre os sujeitos e/ou formadores e seus dispositivos e narrativas de formação, a exemplo dos conteúdos, tecnologias, objetos de aprendizagem e o próprio universo cultural e comunicacional dos sujeitos" (p.55). Por seu turno, Piementel (2010, p.15), baseando-se em Nunes (1992), considera a EAD como uma modalidade em que "as condutas docentes acontecem à parte das discentes, de tal maneira que a comunicação entre o professor e o estudante se possa realizar mediante textos impressos, por meios eletrónicos, mecânicos ou por outras técnicas". Para Duggleby (2002, p. 4), a EaD assume, uma tipologia de ensino oferecido por correspondência bidirecional, através de "livros e outros materiais em suporte de papel (...) [envolvendo uma interação presencial em tempo e/ou lugar em sistemas de tutoria]".

Nos programas de EAD, é característico, em muitas literaturas, o destaque da separação física entre atores do processo de ensino-aprendizagem. Há, aqui, uma tonalidade de desfasamento de interação, entre o polo de emissão (professor/instituição formadora) e o polo de receção (aluno, enquanto destinatário último do conteúdo). Gomes (2004, p.54) referindo Holmberg (1995), entende que em programas de educação e formação não-contíguas, a comunicação entre a organização de suporte e o aluno, é geralmente mediada por meio de materiais pré-enviados pelo professor. Porém, a autora, alerta que na tentativa de "ascender as relações dialogais" em sede da comunicação bilateral, onde o câmbio de mensagens diversas, às vezes, resvala em tédio, devido a demasiada assincronidade. Portanto, Gomes (2004) alerta que a falta de feedback dos professores, muitas vezes inocentes, devido a irregularidade da bidirecionalidade dos meios de transporte do material, em programas basicamente suportados por tecnologias de material impresso, leva os alunos ao exercício de uma "falsa e perigosa democracia" e autogovernar os destinos da sua formação.

\section{Vantagens de estudar a distância}

Contrariamente ao ensino presencial, esta modalidade, devido às suas, peculiares e caraterísticas, tem vindo a estender-se, desde a cidade até ao campo, chegando muitas vezes à recóndita comunidade alargando oportunidades de oferta e frequência de cursos diversos, sobretudo os de especialização, graduação e pósgraduação, a muitas pessoas cuja natureza das suas vidas pessoal, familiar e profissional, não é proporcional à frequência de cursos presenciais. Por outro lado, no contexto de cumprimento da política de "educação para todos", a EAD afigura-se como uma das alternativas para a difusão do conhecimento a pessoas que não dispõem do tempo convencional das instituições de ensino, na modalidade presencial (Duggleby, 2002; Tumbo, 2016).

$\mathrm{Na}$ sequência de proporcionar possibilidades de formação por via da EAD, a Universidade Pedagógica de Moçambique, através do Centro de Educação Aberta e à Distância (CEAD), propôs-se, entre os seus objetivos, asegurar:

i. maior equidade na área de formação de professores no território nacional; ii. promover cursos de formação inicial e em serviço aos professores do Ensino Secundário Geral (ESG) e a outros quadros, tais como, professores primários, formadores dos Institutos de Formação de Professores (IFP), Institutos do Magistério Primário (IMAP), diretores de escolas, diretores distritais e inspetores da educação;

iii. contribuir com a melhoria da qualidade de ensino através da formação inicial e em serviço de professores sem retirá-los das suas zonas de origem ou de trabalho;

iv. reduzir progressivamente os custos de formação de quadros da educação;

v. responder à crescente demanda de acesso ao ensino superior no país;

vi. aumentar o número de graduados nos cursos oferecidos pela instituição (CEAD, 2010).

Indo ao encontro destas aceções, a EAD elenca enúmeras vantagens. Segundo Duggleby (2002, pp. 8-9), esta modalidade é bastante concorrida, sobretudo por profissionais, pela sua capacidade de resposta às necessidades de formação e/ou atualização dos indivíduos, sem operar alterações no seu "modus vivendi", como por exemplo: acesso a um vasto leque de conhecimentos, competências e qualificações; a pessoas com dificuldades de assumirem compromissos que impliquem horários rígidos, como, por exemplo, as que trabalham em turnos podem estudar sempre que tiverem oportunidades; os cursos podem ser frequentados por pessoas que têm múltiplas obrigações e exigências de tempo, tais como quem trata de crianças pequenas ou trabalha a tempo inteiro; permite a possibilidade de estudar a pessoas que vivem em locais remotos e longe das instituições de ensino; não é desperdiçado tempo nas deslocações até à instituição de ensino, nem à espera de um transporte público (quando existe). Esta modalidade também é uma opção mais barata, principalmente para alunas que são mães, poupando gastos em remunerar pessoal para cuidar das crianças. Também os candidatos já empregados podem prosseguir seus estudos sem perda de rendimentos, uma vez que não têm que renunciar ao trabalho a favor da sua formação.

\section{Condições de acesso aos cursos}

O ingresso aos cursos do primeiro ciclo na UP, nos três regimes em oferta, nomeadamente presencial, póslaboral e à distância, é determinado pelos exames de admissão, nos termos do estabelecido pela Lei ${ }^{\circ} 5 / 2003$, de 21 de janeiro, que regula a atividade do ensino superior. Aos alunos candidatos à EAD as exigências passam das gerais para específicas, satisfazendo as condições apresentadas na Tabela 1. 
Tabela 1.

Requisitos gerais e específicos para a admissão aos cursos EAD

\begin{tabular}{|c|c|}
\hline Gerais & Específicos \\
\hline $\begin{array}{l}\text { - Graduados do ensino } \\
\text { secundário geral que } \\
\text { tenham concluído a } 12^{\mathrm{a}} \\
\text { classe do Sistema } \\
\text { Nacional de Educação } \\
\text { (SNE); } \\
\text { - Graduados habilitados } \\
\text { com nível equivalente } \\
\text { à } 12^{\mathrm{a}} \text { classe do sne, } \\
\text { para continuação dos } \\
\text { estudos; }\end{array}$ & $\begin{array}{l}\text { - Ter habilidades no uso do } \\
\text { computador e facilidade com } \\
\text { internet; } \\
\text { - Estar disponível para realizar o } \\
\text { estudo das disciplinas } \\
\text { programadas; } \\
\text { - Estar disponível a participar em } \\
\text { sessões presenciais e outras } \\
\text { realizações de agrupamento aos } \\
\text { sábados e domingos; } \\
\text { - Procurar ajuda do tutor sempre que } \\
\text { tiver problemas; } \\
\text { - Reportar as dificuldades } \\
\text { encontradas durante o processo de } \\
\text { aprendizagem ao tutor; } \\
\text { - Planificar suas horas do estudo; } \\
\text { - Gerir de forma eficaz o seu tempo } \\
\text { para cumprir prazos. }\end{array}$ \\
\hline
\end{tabular}

Em EAD, o aluno é, em geral, um ser adulto, responsável e principal decisor sobre o destino da sua formação, podendo até flexibilizar o horário de estudo; em vários casos, a aluno é chamado a coexistir suas vidas familiar, social e profissional com a académica, sem se deslocar, frequentemente, para a busca de ações de formação na Instituição formadora. Gomes (2004, p.100), caraterizando o perfil dos alunos da EAD, entende que são geralmente pessoas, “autónomas instrumental e emocionalmente" que assumem comportamentos, atitudes e disciplina própria na realização de tarefas buscando assertividade junto do seu tutor.

\section{Metodologia}

A metodologia de pesquisa utilizada, quanto aos objetivos, é do tipo descritiva. Empregou-se com intenção de descrever as caraterísticas, nomeadamente, de idade, sexo, procedência, nível de escolaridade, estrato socioeconómico, traços da personalidade, entre outros, de grupos de uma determinada população. Quanto aos procedimentos técnicos de coleta de dados, a pesquisa foi do tipo survey. Em estudos de natureza survey, geralmente, objetiva-se analisar uma certa população considerando suas caraterísticas, contextos ou simplesmente ecologias da ocorrência de fenómenos em determinado momento com dimensões de abrangência e globalidade (Afonso, 2005).

$\mathrm{O}$ instrumento utilizado foi submetido a um processo de validação por sete professores e/ou investigadores afro-luso-brasileiros que atuam em Educação a Distância, entre os meses de maio e junho de 2016; em seguida, fez-se o lançamento e preenchimento online (através do link: https://docs.google.com/forms/d/e/1FAIpQLSemPQJf01 De4YK5qvJ1hDE5LPq9CSoNQDjuXwUNmsChlM_04 $\mathrm{Q} /$ viewform?c=0\&w) entre os meses de agosto e novembro de 2016. Obtiveram-se-se 249 respostas válidas, de uma população de 649, representando uma taxa de retorno de $38,4 \%$.

Das oito dimensões do questionário, foram analisados para este artigo os dados sociodemográficos referentes a primeira dimensão, composta por questões que trataram de: curso, faixa etária, sexo, formação académica, situação profissional, tempo de lecionação para os que são professores e as razões de opção pelo curso em EAD. Ou seja, dados que nos permitem traçar o Perfil dos Alunos em EAD Universidade Pedagógica de Moçambique, Delegação de Niassa (UPNI). Os dados obtidos foram sujeitos a um tratamento estatístico, com a utilização de softwares MS EXCEL e SPSS versão 24.

\section{Análise e interpretação dos resultados}

Os resultados, que a seguir são analisados e interpretados, provêm de 249 alunos dos cursos de Licenciatura em AGE, EB e EI da UPNI. Importa realçar que este número representa $38,4 \%(n=649)$ do universo populacional, constituído por alunos que frequentaram os cursos oferecidos em regime de EAD, no ano letivo 2016 na UPNI.

\section{Curso}

Tabela 2.

Distribuição da amostra por cursos

\begin{tabular}{lcc}
\hline Cursos & Fr & \% válida \\
Licenciatura em AGE & 102 & 41,0 \\
Licenciatura em EB & 119 & 47,8 \\
Licenciatura em EI & 28 & 11,2 \\
Total & 249 & 100,0 \\
\hline
\end{tabular}

A distribuição da amostra, conforme a Tabela 2, permitiu perceber que o maior percentual de respondentes pertence ao curso de Licenciatura em EB, com 119 alunos (47,8\%), seguido do curso de Licenciatura em AGE com 102 alunos, correspondentes a $41 \%$. O curso de Licenciatura em EI teve baixo número de respondentes em comparação com os outros dois, 28 alunos $(11,2 \%)$, explicado pelo fato de este curso possuir, apenas, 39 alunos inscritos ${ }^{1}$. Já os cursos de AGE e EB apresentam universos populacionais muito altos, com 398 e 212 alunos, respetivamente, que frequentaram os cursos oferecidos em EAD, até dezembro de 2016 (UPNI, 2016).

\footnotetext{
${ }^{1}$ Relatório, UPNI, 2016
} 


\section{Faixa etária}

Tabela 3.

Distribuição de alunos por idade (em anos) e por curso

\begin{tabular}{lccccc} 
Idade & & AGE & EB & EI & Total \\
& Contagem & 17 & 67 & 4 & 88 \\
20 a 30 & \% do Curso & $16,7 \%$ & $56,3 \%$ & $14,3 \%$ & $35,3 \%$ \\
& \% do Total & $6,8 \%$ & $26,9 \%$ & $1,6 \%$ & $35,3 \%$ \\
& Contagem & 62 & 42 & 22 & 126 \\
\multirow{3}{*}{31 a 40} & \% do Curso & $60,8 \%$ & $35,3 \%$ & $78,6 \%$ & $50,6 \%$ \\
& \% do Total & $24,9 \%$ & $16,9 \%$ & $8,8 \%$ & $50,6 \%$ \\
& Contagem & 21 & 8 & 2 & 31 \\
41 a 50 & \% do Curso & $20,6 \%$ & $6,7 \%$ & $7,1 \%$ & $12,4 \%$ \\
& \% do Total & $8,4 \%$ & $3,2 \%$ & $0,8 \%$ & $12,4 \%$ \\
& Contagem & 2 & 2 & 0 & 4 \\
+ de 51 & \% do Curso & $2,0 \%$ & $1,7 \%$ & $0,0 \%$ & $1,6 \%$ \\
& \% do Total & $0,8 \%$ & $0,8 \%$ & $0,0 \%$ & $1,6 \%$ \\
& Contagem & 102 & 119 & 28 & 249 \\
Total & \% em 1.2. & $100,0 \%$ & $100,0 \%$ & $100,0 \%$ & $100,0 \%$ \\
& Curso & & & & \\
& \% do Total & $41,0 \%$ & $47,8 \%$ & $11,2 \%$ & $100,0 \%$ \\
\hline
\end{tabular}

De acordo com os dados da Tabela 3, referentes a idades dos alunos, percebe-se que há concentração da maioria no intervalo de 31 a 40 anos $(n=126 ; 50,6 \%)$, seguidos de idades compreendidas entre 20 a 30 anos $(\mathrm{n}=88 ; 35.3 \%), 41$ a 50 anos $(\mathrm{n}=31 ; 12,4 \%)$ e mais de 50 anos $(n=4,1,6 \%)$. Na distribuição individual por cursos, o curso de AGE registou um percentual maior $(60,8 \%)$ na faixa etária dos 31 a 40 anos em relação aos inquiridos no curso (102 alunos); em relação à amostra $(n=249)$, os 62 alunos situados nesta faixa, representam 24,9\%. Podese perceber, ainda, que no curso de EB, 67 alunos $(56,3 \%)$ da amostra do curso $(n=119)$ têm as suas idades situadas na faixa etária de 20 a 30 anos, exercendo um peso de $26,9 \%$ dos participantes $(n=249)$.

$\mathrm{O}$ curso de EI registou uma maioria esmagadora no intervalo dos 31 a 40 anos, tendo registado 22 observações correspondentes a $78,6 \%$ e $8,8 \%$ do curso $(n=28)$ e da amostra $(n=249)$. Como também se pode perceber que as faixas etárias dos 20 a 30 e dos 31 a 40 anos, cumulativamente, registaram maior número de frequências, sendo 214 alunos (88 e 126 respetivamente), representando um percentual de $85,9 \%$ da amostra $(n=249)$. Esta percentagem revela, segundo muitas literaturas, que a maioria dos indivíduos com idades situadas entre os 20 a 40 anos, já estão em exercício laboral com maior desejo em frequentar cursos superiores e/ou outros de natureza técnico-profissionais sem se desvincular das suas vidas familiar e profissional.

Os programas de educação e formação oferecidos em regime de EAD, possibilitam ao estudante mais autonomia e responsabilidade na tomada de decisões sobre a sua formação, em seu ambiente natural e sociocultural, "envolvendo pessoas, equipamentos e materiais [constituídos por sua família, amigos, colegas de serviço, material de apoio aos estudos]" que motivem o aluno em sua aprendizagem a distância (Delling, 1987, referido por Gomes, 2004, p. 90). Uma outra análise feita em torno dos alunos com idades situadas entre os 20 e 30 anos mostra que a distribuição nesta faixa aponta para 88 alunos $(35,3 \%)$ do total $(n=249)$. Pela contagem tempotal apura-se que estes nasceram na década de 1990, coincidindo com a idade da web. Segundo Prenski
(2001), este grupo pertence à geração de "nativos digitais", que pelas suas habilidades de navegação na $w e b$, passam horas ligados às tecnologias digitais e internet e demandam à escola a sua aceitação, que passa pela mobilização de uma nova pedagogia em cursos oferecidos em EAD, baseada na web. Esta influência pode contribuir para a criação e dinamização de comunidade virtual, caraterizado pela partilha de informações no ciberespaço, por meio de tecnologias emergentes, a serem propostas à UPNI para explorá-las, a favor de cursos oferecidos em regime de EAD.

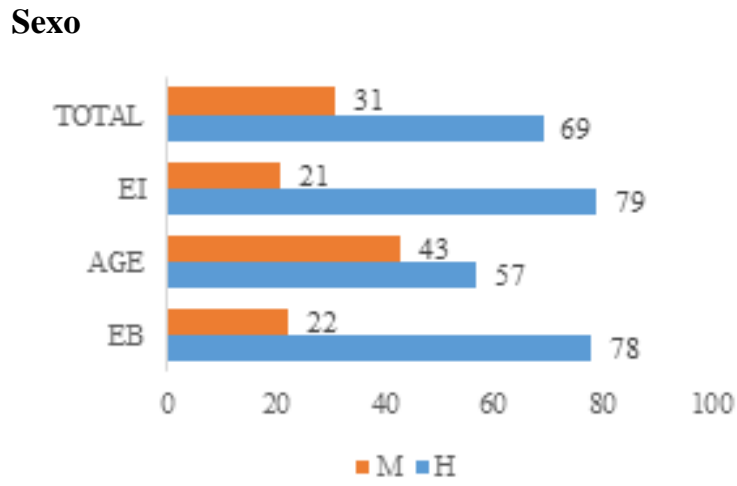

Gráfico 1. Distribuição dos alunos segundo sexo

No contexto geral, constata-se no Gráfico 1, a predominância do sexo masculino $(n=173 ; 69 \%)$. Na análise individual por curso, também se observou maior abundância dos homens em relação as mulheres. No curso de AGE, há uma aproximação dos percentuais de ambos sexos, sendo $57 \%$ e $43 \%$ para masculino e feminino $(\mathrm{n}=102)$ respetivamente.

Nos cursos de Licenciatura em EI e EB, verifica-se grande amplitude entre os sexos. No curso de EI $(n=28)$ as alunas (sexo feminino) representam $21 \%$ ao passo que $79 \%$ são alunos (sexo masculino); no curso de EB, ainda, se notabiliza a expressão masculina com $78 \%$ contra $22 \%$ $(\mathrm{n}=119)$. Com as largas possibilidades oferecidas pela EAD, de conciliar a gestão doméstica e os estudos, as mulheres são convocadas a se emanciparem em programas de formação (Da Luz, 2013), contudo, para o caso em estudo, verifica-se que representam ainda uma minoria em relação aos homens.

\section{Formação académica}

Os resultados do estudo mostram que os cursos EAD, na delegação investigada, são concorridos por alunos com Nível Médio Profissional (NMP), provenientes do Ensino Técnico Profissional, equivalente à $12^{\mathrm{a}}$ classe do Sistema Nacional de Educação, que lhes permite a continuação dos estudos no Ensino Superior. Estes (197 alunos) representam $79,1 \%$ do total dos alunos $(n=249)$ contra $52(20,9 \%)$ dos restantes, ou seja, alunos com Nível Médio Geral, provenientes do Ensino Secundário Geral (ESG).

Uma apreciação separada mostra que o curso de AGE apresenta um percentual muito alto $(84,3 \%)$ de alunos cujo ingresso dependeu da conclusão do NMP. Ao passo que os restantes cursos destacam-se por assinalar percentagens demasiadamente próximas $(75,6 \%$ e $75 \%$ para EB e EI respetivamente) de alunos que ingressaram 
após a conclusão do NMP. Uma conclusão preliminar esclarece que a minoria proveniente das escolas do ESG $(20,9 \%)$, para este caso, é que teve "portas abertas" aos cursos, o que atraiu ao investigador o interesse em buscar resposta mais esclarecida desta dispersão.

Ao longo da investigação, esta desigualdade de oportunidades foi explicada, por diversos fatores, nomeadamente: a falta de apetência dos jovens, recéns graduados do ESG, em frequentar cursos ligados à educação, particularmente à docência; os memorandos de entendimento assinados entre a UP e outras Instituições do Estado para ingressos diretos à Universidade sem exames de admissão; a entrada em massa de alunos, exercendo a carreira docente no ensino primário e secundário, por meio de concurso documental e avaliação do currículo académico e profissional até ao ano letivo 2013.

\section{Motivos da opção do curso em EAD}

Na generalidade, os três cursos estudados, apresentam percentagens muito expressivas quanto às razões da opção em frequentar um curso em EAD, destacando-se: não ter que se deslocar à universidade, compatibilidade de horário e atendimento aos intereses dos alunos. No que diz respeito ao motivo de "não ter que se deslocar à universidade", obteve-se 36,9\%, 34,5\% e $10 \%$ para, respetivamente, $\mathrm{EB}, \mathrm{AGE}$ e $\mathrm{EI} ;$ quanto à "compatibilidade de horário", assinalou-se para AGE $(36,1 \%)$ e $\operatorname{EB}(31,7 \%)$; no "atendimento às minhas necessidades", os três cursos registaram $30,5 \%, 29,3 \%$ e 9,6\% para EB, AGE e EI respetivamente. Os restantes motivos, de "mercado de trabalho" e "qualidade de ensino ministrado no curso", registaram baixos percentuais, sendo o motivo de mercado de trabalho explicado pelo fato de muitos alunos $(229=92 \%)$ serem já empregados.

Tabela 4.

Motivo de opção por um curso em EAD

\begin{tabular}{lll}
\hline Motivo de opção por um curso em EAD & fr & $\%$ \\
Qualidade do ensino ministrado no curso & 42 & 16,9 \\
Mercado de trabalho & 67 & 26,9 \\
Atendimento aos meus interesses & 173 & 69,5 \\
Compatibilidade de horário & 194 & 77,9 \\
Não ter que me deslocar à universidade & 203 & 81,5 \\
Outros & 2 & 0,8 \\
\hline
\end{tabular}

Estes indicadores, nomeadamente as razões "não ter que me deslocar à universidade; compatibilidade do horario; atendimento aos meus intereses; mercado de trabalho; e qualidade do ensino ministrado no curso", mesmo esta última apesar da pouca relevância na opinião dos alunos (mencionada apenas poer 16,9\% dos alunos), devem ser tomados em conta no desenho e implementação de cursos $\mathrm{EAD}$, devidos às razões de ordem sociais, económicas e geográficas, particularmente da Província de Niassa, onde muitos alunos que frequentam os cursos EAD são professores provenientes de todos distritos da Província, que se debatem com problemas de vias de acesso, funcionamento irregular dos transportes, alto custo de passagens de transportes bidirecionais (local de trabalho/casa ao centro de recursos da UPNI), auferem salários baixos (Preti, 2010). Com a atual tecnología digital é possível oferecer cursos com Qualidade pedagógica, colocando alunos e professores a dialogarem em hipermobilidade (em tempos e espaços diferentes), na companhia das suas famílias (Silva \& Souza, 2015).

\section{Considerações finais}

Este estudo permitiu obter uma radiografia das caraterísticas sociodemográficas dos alunos que procuram os cursos oferecidos em EAD pela UPNI. Os resultados permitiram perceber que a clientela destes cursos é constituída por indivíduos que já desempenham alguma atividade profissional, sendo de destacar a função docente. Uma parcela, não muito significativa, de alunos provém do ESG, o que denuncia que os jovens não revelam apetência em frequentar cursos ligados à educação, particularmente à docência que esta modalidade oferece nesta delegação.

Os resultados permitem, à semelhança das considerações do CEAD, concluir que a EAD abre muitas possibilidades de frequência de cursos superiores a milhares de alunos, com maior destaque os professores, muitos deles residentes nas zonas rurais. Percebeu-se que ainda existe desigualdades de oportunidade em temos de género e idade, sendo o sexo masculino e a faixa etária de 31 a 40 anos, mais representados na generalidade dos cursos estudados.

Notabilizou-se que os alunos optam em frequentar cursos em regime de ensino a distância, por esta permitir, a combinação de diversas ecologias da vida quotidiana dos alunos, sem terem que se deslocar, de forma frequente, à Universidade, fazendo a sua formação em horários mais flexíveis e compatíveis ao do trabalho, atendendo, desta forma, aos interesses e vontades profissioanis e pessoais dos alunos.

\section{Referências Bibliográficas}

Afonso, N. (2005). Investigação Naturalista em Educação: Um guia prático e critíco. Porto: Edições ASA.

CEAD (2015). Relatório de prestação de contas. Maputo: S/Ed (policopiado).

Da Luz, Luciane. Mulheres e EAD: uma análise de gênero sobre o perfil dos (as) acadêmicos (as) na educação a distância no Brasil. Maiêutica-Serviço Social, v. 1, n. 1, 2013.

Duggleby, J. (2002). Como ser um Tutor online. Lisboa: Monitor;

Gomes, M. J. (2004). Educação a distância. Braga: Universidade do Minho.

Piementel, N.M. (2010). Educação a distancia. Rio de Janeiro: Fundação CECIERJ.

Prensky, M. (2001). Digital natives, digital immigrants. On the Horizon. NCB University Press, Vol. 9 No. 5, Outubro.

Santos, E. (2014). Pesquisa-formação na Cibercultura. Santo Tirso: Whitebooks;

Preti, O. (2014). A Universidade Aberta do Brasil em Moçambique: A experiência de um programa de 
cooperação internacional no continente africano. Revista Pesquisa e Debate em Educação, 3(1).

Santos, E. (2014). Pesquisa-formação na Cibercultura. Santo Tirso: Whitebooks;

Silva, B. D., \& Souza, K. P. (2015). Coinvestigar a distância em tempos de cibercultura: relato de uma experiência sobre coempreender. Revista da FAEEBAEducação e Contemporaneidade, 24 (44), pp. 55-68.

Tumbo, D. L. (2016). O sistema de gestão de aprendizagem suportado pelas tecnologias digitais de informação e comunicação (TDIC) em educação a distância (ead)-um desafio para a universidade pedagógica de moçambique1. Technology Enhanced Learning and Societal Challenges, 32.

UPNI (2016). Relatório anual. Lichinga-Niassa: S/Ed (policopiado).

\section{Sites consultados}

http://www.mctestp.gov.mz/?q=content/institui $\% \mathrm{C} 3 \% \mathrm{~A}$ 7\%C3\%B5es-de-es

https://www.up.ac.mz/

Moçambique. Lei no 04/1983 - Lei do Sistema Nacional de Educação. Disponível em: http://www.portaldogoverno.gov.mz/docs_gov.

Moçambique. Decreto 35/2009 - Aprova o Regulamento do Ensino à Distância. Disponível em: http://www.portaldogoverno.gov.mz/docs_gov.

\section{Agradecimentos}

Este artigo de pesquisa foi desenvolvido no âmbito do Programa Doutoral "Technology Enhanced Learning and Societal Challenges", apoiado pela Fundação para a Ciência e a Tecnologia (FCT) - Portugal, contrato \# PD/00173/2014. Foi também apoiado pelo Instituto de Bolsas de Estudo (IBE)-Moçambique. 